\title{
Structural elements within the methylation loop (residues 112-117) and EF hands III and IV of calmodulin are required for Lys ${ }^{115}$ trimethylation
}

\author{
Jennifer A. COBB, Chang-Hoon HAN, David M. WILLS and Daniel M. ROBERTS ${ }^{1}$ \\ Department of Biochemistry, Cellular and Molecular Biology, The University of Tennessee, Knoxville, TN 37996-0840, U.S.A.
}

Calmodulin is trimethylated by a specific methyltransferase on Lys $^{115}$, a residue located in a six amino acid loop (LGEKLT) between EF hands III and IV. To investigate the structural requirements for methylation, domain exchange mutants as well as single point mutations of conserved methylation loop residues $\left(\right.$ E114A, Glu ${ }^{114} \rightarrow$ Ala; L116T, Leu ${ }^{116} \rightarrow$ Thr) were generated. E114A and L116T activated cyclic nucleotide phosphodiesterase (PDE) and $\mathrm{NAD}^{+}$kinase (NADK) similar to wild-type calmodulin, but lost their ability to be methylated. Domain exchange mutants in which EF hand III or IV was replaced by EF hand I or II respectively ( $\mathrm{CaM}^{1214}$ and $\mathrm{CaM}^{1232}$ respectively) showed a modest effect on PDE and NADK activation (50 to $100 \%$ of wild-type), but calmodulin methylation was abolished. A third domain exchange mutant, $\mathrm{CaM}^{\mathrm{EKL}}$, has the methylation loop sequence placed at a symmetrical position between EF hands I and II in the N-terminal lobe [residues $\mathrm{QNP}^{(41-43)}$ replaced by
EKL]. CaM ${ }^{\mathrm{EKL}}$ activated PDE normally, but did not activate NADK. However, CaM ${ }^{\mathrm{EKL}}$ retained the ability to bind to NADK and inhibited activation by wild-type calmodulin. Site-directed mutagenesis of single residues showed that $\mathrm{Gln}^{41}$ and $\mathrm{Pro}^{43}$ substitutions had the strongest effect on NADK activation. Additionally, $\mathrm{CaM}^{\mathrm{EKL}}$ was not methylated, suggesting that the introduction of the methylation loop between EF hands I and II is not adequate for methyltransferase recognition. Overall the data indicate that residues in the methylation loop are essential but not sufficient for methyltransferase recognition, and that additional residues unique to EF hands III and IV are required. Secondly, the QNP sequence in the loop between EF hands I and II is necessary for NADK activation.

Key words: calcium, methyltransferase, $\mathrm{NAD}^{+}$kinase.

\section{INTRODUCTION}

Calmodulin is a highly conserved calcium sensor protein that is ubiquitous among eukaryotes, and modulates the activities of multiple enzymes. Calmodulin is a monomer consisting of two structurally similar globular calcium-binding lobes [1] attached with a flexible linker region [2,3]. Each lobe consists of two helixloop-helix EF hand calcium binding sites, with EF hand domains I and II constituting the N-terminal lobe and EF hands III and IV constituting the C-terminal lobe of the protein. EF hands I and II share sequence similarity [4] and structural similarity [1,5] with EF hands III and IV respectively. Additionally, this symmetry is also evident in the structures of the mutant calmodulin $(\mathrm{CaM})$-peptide complexes in which these EF hand pairs are related by an approximate two-fold axis [6,7].

Calmodulin is commonly found to be post-translationally trimethylated on a single lysine residue at position 115 (reviewed in [8]). Lys ${ }^{115}$ is a solvent exposed residue that is found on a highly conserved six amino acid loop-turn region (LGEKLT) located between the helix 6 of the EF hand III and the helix 7 of the EF hand IV (Figure 1). Although post-translational methylation occurs on many calmodulin proteins, its biological significance has remained a mystery. Previous work showed that trimethylation can affect certain in vitro activities of calmodulin, such as the ability to activate plant $\mathrm{NAD}^{+}$kinase (NADK) $[9,10]$, as well as the ability to undergo ubiquitination in vitro [11]. Further, mutations at residue 115 lead to abnormal phenotypes and enhanced defence responses in plants $[10,12,13]$, and to a reduced stability of the protein and growth arrest in Schizosaccharomyces pombe [14].

Trimethylation of Lys ${ }^{115}$ is catalysed by an $N$-methyltransferase that utilizes $S$-adenosyl methionine as a co-substrate, and which shows a high specificity for calmodulin ([15-19]; reviewed in [8]). This suggests that a highly specific calmodulin methyltransferase co-evolved with calmodulin with the dedicated function of trimethylating Lys ${ }^{115}$. Previous kinetic studies have shown that the site on calmodulin recognized by the calmodulin $\mathrm{N}$ methyltransferase resides solely on the C-terminal lobe (residues 78-148) [17]. Further, methyltransferase binding and catalysis is affected by ionic strength, calcium-binding to calmodulin, and calmodulin antagonists [16-19]. Additionally, mutations or oxidation of residues in the hydrophobic core of the C-terminal lobe eliminate methyltransferase recognition [17,20,21]. Thus, it is likely that the site on calmodulin bound by the enzyme is more complex than the simple availability of a solvent exposed lysine residue. However, beyond these preliminary studies, the specific features of the calmodulin C-terminal lobe that lead to methyltransferase recognition and specificity remain unresolved.

In the present study we have investigated the structural requirements for calmodulin methylation by: 1) site-directed mutagenesis of conserved residues in the methylation loop-turn sequence; 2) attempting to engineer a calmodulin methyltransferase recognition site at the symmetrical loop-turn region between EF hands I and II in the N-terminal lobe; and 3) substitution of EF hands III and IV in the C-terminal lobe with EF hands I and II respectively. Additionally, during the course

Abbrevations used: CaM, mutant calmodulin; NADK, NAD ${ }^{+}$kinase; PDE, cyclic nucleotide phosphodiesterase; VU-1, calmodulin derived from a synthetic gene.

1 To whom correspondence should be addressed (e-mail drobert2@utk.edu). 


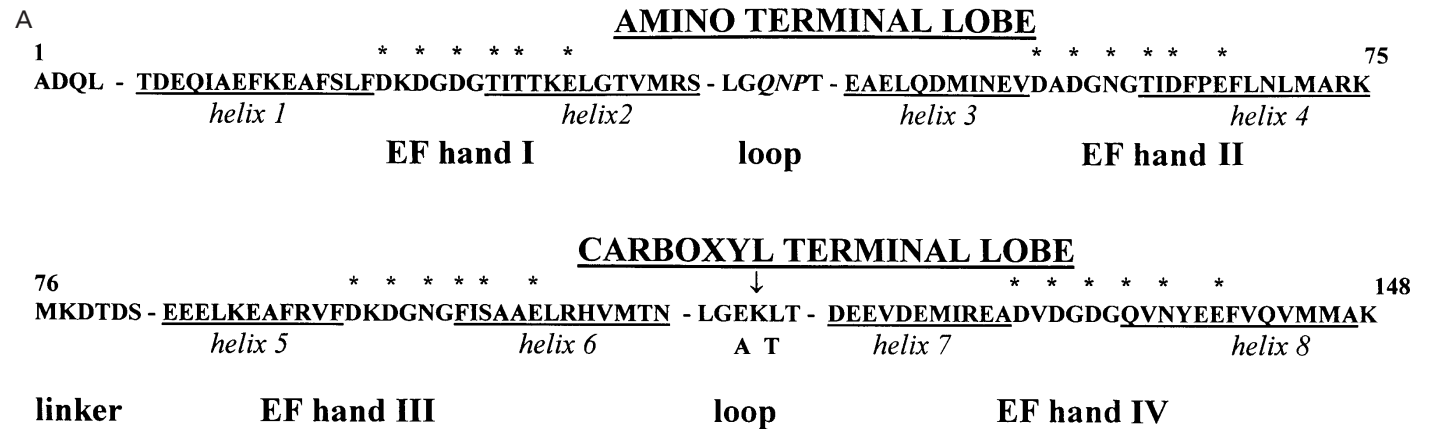

B
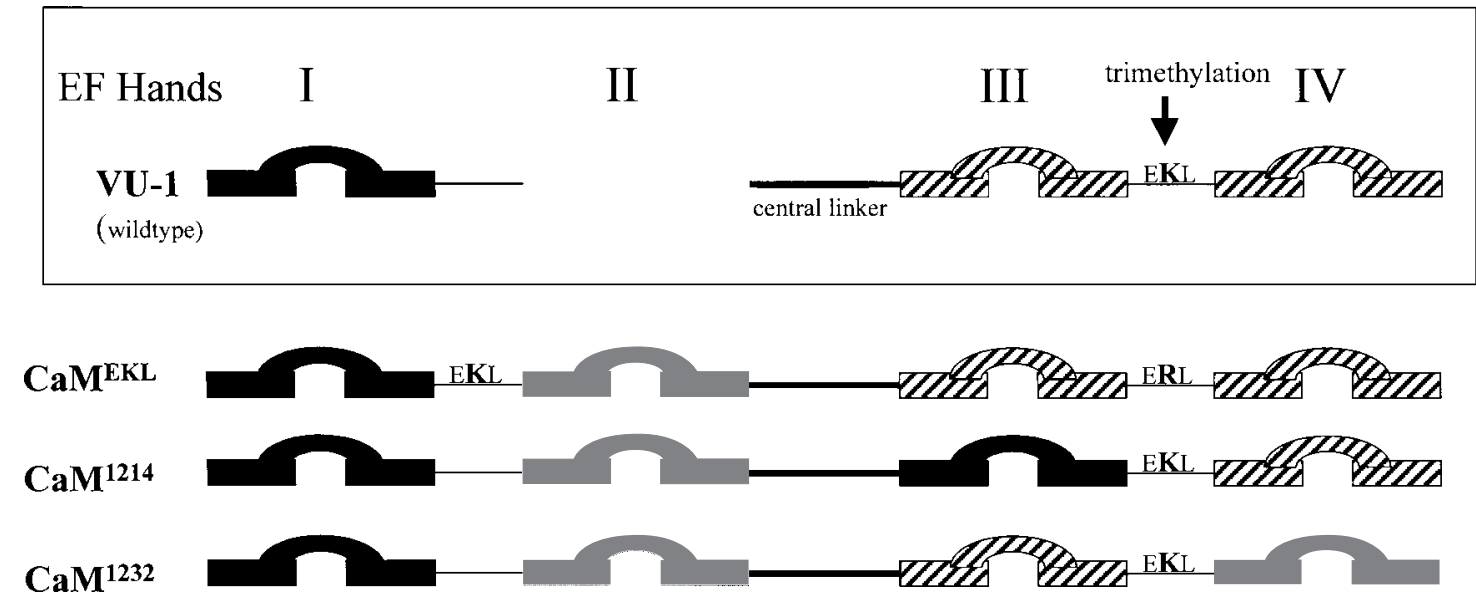

Figure 1 Sequence and domain organization of calmodulin and calmodulin mutants

(A) Sequence of VU-1 (calmodulin derived from a synthetic gene) showing the location of EF hands I to IV, the central linker region, and the two loops between the EF hands. $\alpha$-Helical regions are underlined and calcium ligands are indicated by an asterisk. The three amino acid region, QNP ${ }^{(41-43)}$, replaced by EKL in CaM ${ }^{\text {EKL }}$ is italicized. The site of Iysine methylation is indicated by an arrow. The positions of $\mathrm{Ala}^{114}$ and $\mathrm{Thr}^{116}$ substitutions are indicated. (B) Organization of the domain exchange calmodulin mutants is shown. CaM ${ }^{\text {EKL }}$ has an arginine at position 115 and has

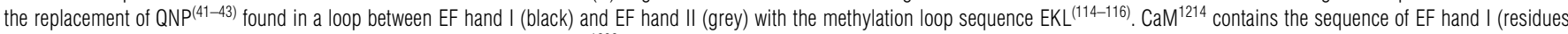
13-39) replacing the sequence of EF hand III (residues 86-112). CaM ${ }^{1232}$ contains the sequence of EF hand II (residues 45-75) replacing the sequence of EF hand IV (residues 118-148).

of this study we have identified residues that appear to be important determinants for calmodulin activation of NADK.

\section{MATERIALS AND METHODS}

\section{Molecular cloning and site-directed mutagenesis techniques}

All mutagenesis and expression experiments were carried out using the calmodulin expression plasmid pVUCH [22] which contains the cloned synthetic calmodulin (VU-1) gene [23]. Synthetic oligonucleotides were obtained either from Oligos Etc. (Bethel, ME, U.S.A.) or Gibco/BRL. Calmodulin mutants E114A, L116T, Q41E, N42K, and P43L were generated using the QuikChange ${ }^{\mathrm{TM}}$ Site-Directed Mutagenesis Kit (Stratagene). $\mathrm{CaM}^{\mathrm{EKL}}$ was generated by cassette mutagenesis of the K115R mutant calmodulin (VU-3) gene [9]. The VU-3 gene was digested with $M s c I$ and PstI to remove a $27 \mathrm{bp}$ region including the coding region for residues 41-43. The synthetic oligonucleotide cassette that follows was ligated into the $M s c \mathrm{I} / P s t \mathrm{I}$-digested plasmid

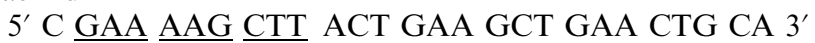

3' G CTT TTC GAA TGA CTT CGA CTT G 5'.

The product introduces a HindIII site, and the modified codons that encode $\mathrm{EKL}^{(41-43)}$ are underlined.
To generate $\mathrm{CaM}^{1214}$ and $\mathrm{CaM}^{1232}$, cassettes containing $\mathrm{EF}$ hands I or II were generated from the $\mathrm{CaM}^{\mathrm{EKL}}$ construct by a PCR approach. The region of the $\mathrm{CaM}^{\mathrm{EKL}}$ sequence (nucleotides 47 to 234) which contains the coding regions for EF hands I and II was amplified. The forward primer (AA GAG GCC TCC TCT TCG TTT GAC AAA G) creates a new StuI site at the 5' end of the fragment, and the reverse primer (GA CTT GGA CTA CCG CGC GTT CAT CTT CGA ACC CGG GAA) creates a new HindIII and introduces a stop codon after residue 75 of EF hand II. This amplified region also contains an additional HindIII restriction site within the loop-turn region between EF hands I and II. The PCR fragment was digested with StuI and HindIII to generate a $80 \mathrm{bp}$ fragment containing the coding region for $\mathrm{EF}$ hand I, and a $107 \mathrm{bp}$ fragment containing the coding region for EF hand domain II. Each fragment was isolated by electrophoresis on $6.5 \%(\mathrm{w} / \mathrm{v})$ polyacrylamide gels in $50 \mathrm{mM}$ Tris/ borate $/ 2 \mathrm{mM}$ EDTA [24]. To generate $\mathrm{CaM}^{1214}$, the $80 \mathrm{bp}$ fragment was cloned into the HindIII/StuI sites of the VU-1 gene [23]. To generate $\mathrm{CaM}^{1232}$, the $107 \mathrm{bp}$ fragment was ligated into the HindIII site of the VU-1 gene. In both calmodulins, the methylation loop-turn sequence (residues 112-117) was regenerated and the only difference from wild-type was the presence of the new EF hand sequences (Figure 1B). 
All expression plasmids were transformed into Escherichia coli JM101 as described previously [25]. Domain exchange mutants were identified by restriction mapping: the loss of an $\mathrm{MscI}$ site for $\mathrm{CaM}^{\mathrm{EKL}}$, and the introduction of a new KpnI site for $\mathrm{CaM}^{1214}$ and a new PstI site for $\mathrm{CaM}^{1232}$. All mutants were confirmed by automated DNA sequencing on a Perkin Elmer Applied Biosystems 373 DNA sequencer at the University of Tennessee Molecular Biology Research Facility (Knoxville, TN, U.S.A.). Sequencing reactions were prepared with a Prism Dye Terminator Cycle sequencing kit (Perkin Elmer Applied Biosystems).

\section{Protein purification}

Calmodulins were prepared from E. coli expression clones as described previously [23,25]. Calmodulin methyltransferase was purified from sheep or pig brain through the calmodulinSepharose step as described previously [17]. Calmodulin-dependent cyclic nucleotide phosphodiesterase (PDE) was purified through the DEAE-cellulose step as described in [26]. Calmodulin-dependent NADK was purified from pea seedlings as described previously [20].

\section{Other analytical methods}

Calmodulin methyltransferase was assayed as described previously [17] in a standard assay buffer containing $0.1 \mathrm{M}$ glycylglycine/ $\mathrm{NaOH}, \mathrm{pH} 8.0,0.15 \mathrm{M} \mathrm{KCl}, 2 \mathrm{mM} \mathrm{MgCl}, 5 \mathrm{mM}$ dithiothreitol, $0.01 \%$ (w/v) Triton X-100, $12 \mu \mathrm{M}$ [methyl- $\left.{ }^{3} \mathrm{H}\right] S$-adenosylmethionine $(1.25 \mu \mathrm{Ci} / \mathrm{nmol}), 1 \mathrm{mM} \mathrm{CaCl}{ }_{2}$, and various amounts of calmodulin. Pea NADK activity was assayed as described previously [23]. PDE assays were carried out as described previously [26]. NADK and PDE activation curves were generated by best fits to the data using the following equation for calmodulin activation:

$\frac{v}{V_{\max }}=\frac{[\mathrm{CaM}]^{n}}{K_{0.5}+[\mathrm{CaM}]^{n}}$

where $v$ is the initial enzyme rate, $K_{0.5}$ is the concentration of calmodulin for half-maximal activation, $V_{\max }$ is the maximal activation of the enzyme, $[\mathrm{CaM}]$ is the concentration of calmodulin, and $n$ represents the Hill coefficient.

Assays for the inhibition of NADK activation by $\mathrm{CaM}^{\mathrm{EKL}}$ were done under standard conditions with various amounts of $\mathrm{CaM}^{\mathrm{EKL}}$ at several fixed concentrations of $\mathrm{VU}-1$ in $1 \mathrm{mM} \mathrm{CaCl}{ }_{2}$. The data were plotted as a Dixon plot using the following equation:

$\frac{1}{v}=\frac{K_{0.5}}{V_{\max } K_{\mathrm{i}}[\mathrm{CaM}]} \cdot\left[\mathrm{CaM}^{\mathrm{EKL}}\right]+\frac{1}{V_{\max }}\left(1+\frac{K_{0.5}}{[\mathrm{CaM}]}\right)$

where $v$ is the initial enzyme rate, $K_{0.5}$ is the concentration of VU1 for half-maximal activation. $V_{\max }$ is the maximal activation of the enzyme, $[\mathrm{CaM}]$ is the concentration of VU- $1,\left[\mathrm{CaM}^{\mathrm{EKL}}\right]$ is the concentration of $\mathrm{CaM}^{\mathrm{EKL}}$, and $K_{\mathrm{i}}$ is the inhibition constant. Assays for the calcium dependence of NADK activation were carried out in $50 \mathrm{mM}$ Hepes/ $\mathrm{NaOH}, \mathrm{pH} 7.5,3 \mathrm{mM} \mathrm{MgCl}_{2}$, $3 \mathrm{mM}$ EGTA, $3 \mathrm{mM}$ ATP, $2 \mathrm{mM} \mathrm{NAD}^{+}, 0.1 \mathrm{mM}$ calmodulin, and various concentrations of $\mathrm{CaCl}_{2}$ that yielded a free calcium concentration ranging from $10^{-8}$ to $10^{-3} \mathrm{M}$ determined as described previously [20]. Free calcium concentrations in the reactions were verified and quantified with fura-2 (Molecular Probes) as described in [27]. All buffers and reagents were decalcified by Chelex-100 resin treatment as described in [28]. Protein concentrations were determined by the bicinchoninic acid assay (Pierce Biochemicals) using BSA as a standard.
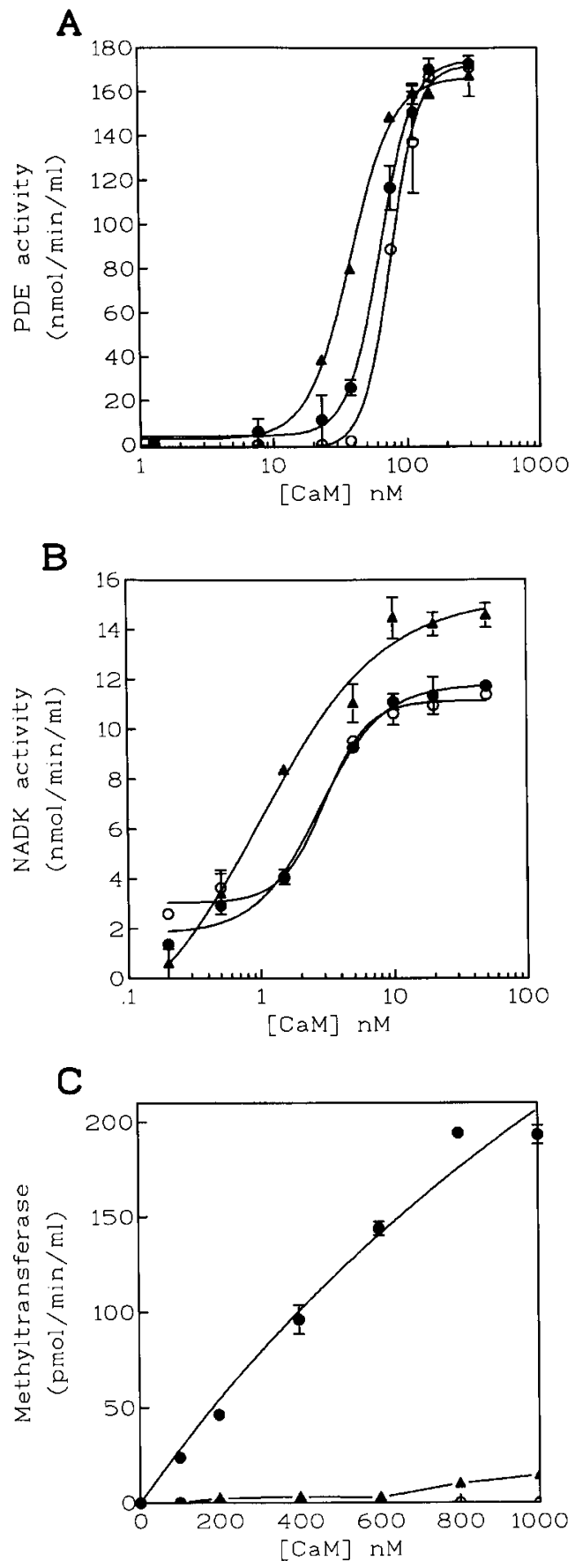

Figure 2 Enzyme activation and methylation of E114A and L116T

Activation of $(\mathbf{A})$ PDE and $(\mathbf{B})$ NADK by VU-1 (O), E114A (O), and L116T ( $\mathbf{A}$ ) calmodulins, and (C) pseudo-first-order methyltransferase kinetics at a constant saturating concentration of S-adenosylmethionine $(12 \mu \mathrm{M})$ with calmodulin as the varied substrate. All assays were carried out in $1 \mathrm{mM} \mathrm{CaCl}_{2}$. Means \pm S.E.M. are shown.

\section{RESULTS}

\section{Effect of point mutations (E114A and L116T) in the methylation loop}

The six amino acid loop-turn sequence that contains the site of methylation (Figure 1A), contains a surface exposed glutamate at position 114 as well as a leucine at position 116 which is 
Table 1 Activation parameters of calmodulin dependent enzymes by methylation loop and domain exchange mutant calmodulins

$V_{\text {max }}$ maximal activation of enzymes (PDE or NADK) by calmodulins standardized to VU-1 $(100 \%) ; K_{0.5}^{\mathrm{CaM}}$, concentration of calmodulin $(\mathrm{nM})$ giving half-maximal activation; $K_{0.5}^{\mathrm{Ca} 2+}$, concentration of calcium (nM) giving half-maximal activation of enzyme NADK in the presence of a constant amount of calmodulin $(0.1 \mu \mathrm{M})$. The S.E.M. value is shown in parentheses; n.d., not determined.

\begin{tabular}{|c|c|c|c|c|c|}
\hline \multirow[b]{2}{*}{ CaM } & \multicolumn{2}{|l|}{ PDE } & \multicolumn{3}{|l|}{ NADK } \\
\hline & $V_{\max }(\%)$ & $K_{0.5}^{\mathrm{CaM}}(\mathrm{nM})$ & $V_{\max }(\%)$ & $K_{0.5}^{\mathrm{CaM}}(\mathrm{nM})$ & $K_{0.5}^{\mathrm{Ca} 2+}(\mathrm{nM})$ \\
\hline VU-1 & 100 & $54(4.2)$ & 100 & $1.8(0.07)$ & 96 \\
\hline $\mathrm{CaM}^{\mathrm{EKL}}$ & 100 & $91(7.8)$ & 0 & 0 & n.d. \\
\hline Q41E & 97 & $85(9.0)$ & 36 & $1.8(0.06)$ & n.d. \\
\hline N42K & 101 & $67(7.4)$ & 80 & $0.8(0.12)$ & n.d. \\
\hline P43L & 101 & $66(8.8)$ & 57 & $2.3(0.06)$ & n.d. \\
\hline $\mathrm{CaM}^{1214}$ & 98 & $98(6.9)$ & 66 & $1.1(0.10)$ & 120 \\
\hline $\mathrm{CaM}^{1232}$ & 52 & $72(10.1)$ & 79 & $0.7(0.05)$ & 148 \\
\hline E114A & 99 & 75 (11.1) & 97 & $3.0(0.07)$ & n.d. \\
\hline L116T & 96 & $38(6.6)$ & 130 & $1.0(0.18)$ & n.d. \\
\hline
\end{tabular}

embedded within the hydrophobic core of the C-terminal lobe [1]. To test the role of these invariant flanking residues in calmodulin methyltransferase recognition, Glu ${ }^{114}$ was substituted with alanine, and $\mathrm{Leu}^{116}$ was replaced by threonine.

The effect of these mutations on the activation of calmodulindependent enzymes was assessed to determine whether calmodulin function was disrupted. The activation of NADK and PDE by E114A was essentially indistinguishable from that by VU-1 (Figures 2A and 2B, Table 1). L116T also retained the ability to fully activate NADK and PDE, and actually showed a slightly enhanced activation of NADK (Figures $2 \mathrm{~A}$ and $2 \mathrm{~B}$, Table 1). In contrast, the E114A and L116T mutations showed a drastic effect on Lys ${ }^{115}$ methylation and neither calmodulin could serve as a substrate for methylation by the calmodulin methyltransferase (Figure 2C). The data suggest that the substitutions of these highly conserved residues on either side of Lys $^{115}$ do not significantly alter their ability to activate calmodulin-dependent enzymes, but that they are essential for methyltransferase recognition.

\section{Attempts to generate a methylation site within the $\mathrm{N}$-terminal lobe using CaM ${ }^{\mathrm{EKL}}$}

While the data in the previous section show that the integrity of the residues in the loop-turn region are essential for methylation, it is not clear whether other structural elements unique to the Cterminal lobe are required. Calmodulin shows symmetry between the $\mathrm{N}$-terminal and $\mathrm{C}$-terminal lobes (Figure 1A), including the presence of a six amino acid loop (LGQNPT) in the N-terminal lobe that is located at a position similar to the methylation loop in the $\mathrm{C}$-terminal lobe (Figure 1A). A comparison of the backbone structure of the two loop regions (residues 39-44 and 112-117) shows that they are superimposable (Figure 3). Taking advantage of the symmetry between the two lobes we investigated whether we could engineer a methylation recognition sequence into the loop region in the $\mathrm{N}$-terminal lobe.

VU-3 $[9,10]$ was used as the starting point for the generation of the mutant $\mathrm{CaM}^{\mathrm{EKL}}$ (Figure 1). Since it has a substitution of an arginine for a lysine at residue 115, it is not methylated by the calmodulin methyltransferase [9,29]. The sequence of the methylation loop (LGEKLT) of the C-terminal lobe was placed in the loop of the N-terminal lobe by substituting the coding region for QNP $^{(41-43)}$ with EKL by cassette-based mutagenesis (Figure 1B).
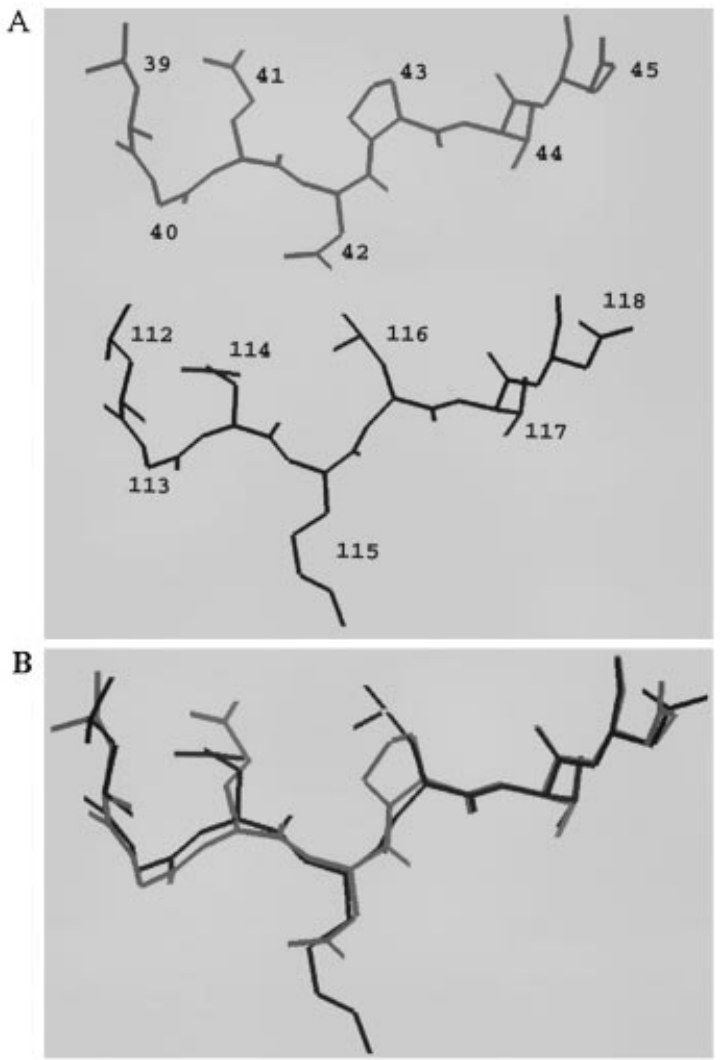

Figure 3 Comparison of the backbone structures of the loop-turn regions in the $\mathrm{N}$ - and $\mathrm{C}$-terminal lobes

The methylation-site loop (LGEKLT, residues 112-117 shown in black) of the C-terminal lobe and its symmetrical loop region (LGQNPT, residues 39-44 shown in grey) of the N-terminal lobe are shown apart $(\mathbf{A})$ and superimposed $(\mathbf{B})$. The two structures superimpose with a rootmean-square difference of $0.33 \AA$. The images were generated using a Silicon Graphics Indigo system and Insight II software.

This substitution showed a complex effect on calmodulin activator activity. Both VU-1 and CaM ${ }^{\mathrm{EKL}}$ activate PDE to the same extent, and compared to $\mathrm{VU}-1, \mathrm{CaM}^{\mathrm{EKL}}$ shows only a slight shift in the concentration required for half-maximal activation $\left(K_{0.5}^{\mathrm{CaM}}\right.$; Figure $4 \mathrm{~A}$, Table 1$)$. This suggests that the three substitutions within this loop in the N-terminal lobe do not drastically affect PDE activator properties. In contrast, $\mathrm{CaM}^{\mathrm{EKL}}$ showed essentially no activation of NADK (Figure 4B). Furthermore, $\mathrm{CaM}^{\mathrm{EKL}}$ was a poor methyltransferase substrate showing essentially no detectable methylation (Figure 4C). Thus, the substitution of the methylation loop sequence at an analogous position in the $\mathrm{N}$-terminal lobe was not adequate to confer methyltransferase recognition, even though the two loops have a similar conformation.

To investigate whether the loss of activation of NADK by $\mathrm{CaM}^{\mathrm{EKL}}$ is the result of an inability of NADK to bind to the mutant calmodulin, the ability of $\mathrm{CaM}^{\mathrm{EKL}}$ to antagonize the activation of NADK by VU-1 was tested (Figure 5A). CaM ${ }^{\mathrm{EKL}}$ was able to inhibit the activation of NADK by VU-1 $\left(K_{\mathrm{i}}=\right.$ $4 \pm 0.25 \mathrm{nM})$. Thus, CaM ${ }^{\mathrm{EKL}}$ binds NADK, but this binding event is non-productive and does not lead to the activation of the enzyme. Previous studies have shown that VU-3 is a potent activator of NADK $[9,10]$. Thus, the aberrant NADK activator activity of $\mathrm{CaM}^{\mathrm{EKL}}$ appears to be due to the substitution of EKL at residues 41-43 and not due to the presence of $\mathrm{Arg}^{115}$. 

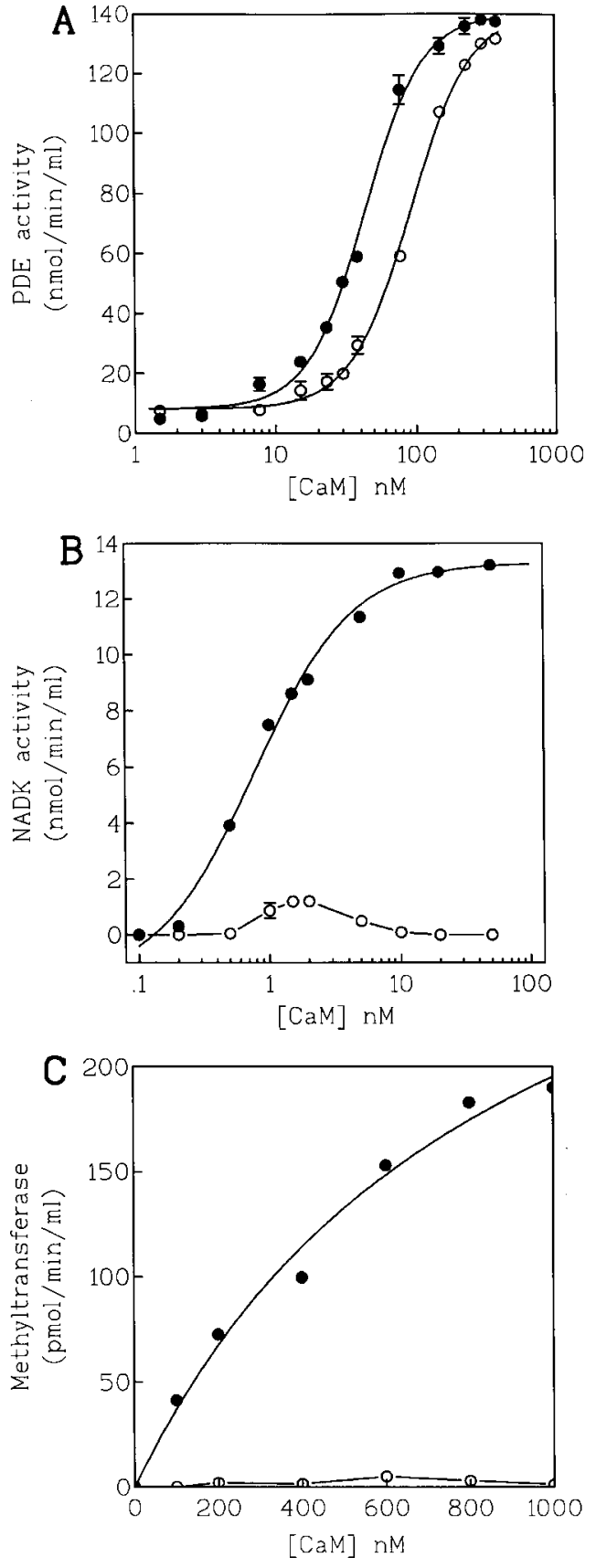

Figure 4 Enzyme activation and methylation of CaM ${ }^{\mathrm{EKL}}$

Activation of (A) PDE and (B) NADK by VU-1 (-) and CaM ${ }^{\mathrm{EKL}}(\mathrm{O})$ calmodulins, and (C) pseudo-first-order methyltransferase kinetics at a constant saturating concentration of $S$ adenosylmethionine $(12 \mu \mathrm{M})$ with calmodulin as the varied substrate. All assays were carried out in $1 \mathrm{mM} \mathrm{CaCl}$. Means \pm S.E.M. are shown.

To further define which residue(s) are important for the activation of NADK three calmodulin mutants with single amino acid substitutions (Q41E, N42K, P43L) in the loop region were generated. Of the three mutants, Q41E showed the most drastic effect, activating the enzyme to $36 \%$ of the level obtained by VU1 (Figure 5B, Table 1). P43L activates NADK to $57 \%$ of the level of VU-1 and also shows a slight shift in the $K_{0.5}^{\mathrm{CaM}}$ (Figure 5B, Table 1). Mutation N42K shows the least effect on NADK activation ( $80 \%$ of wild-type). The data show that the inability
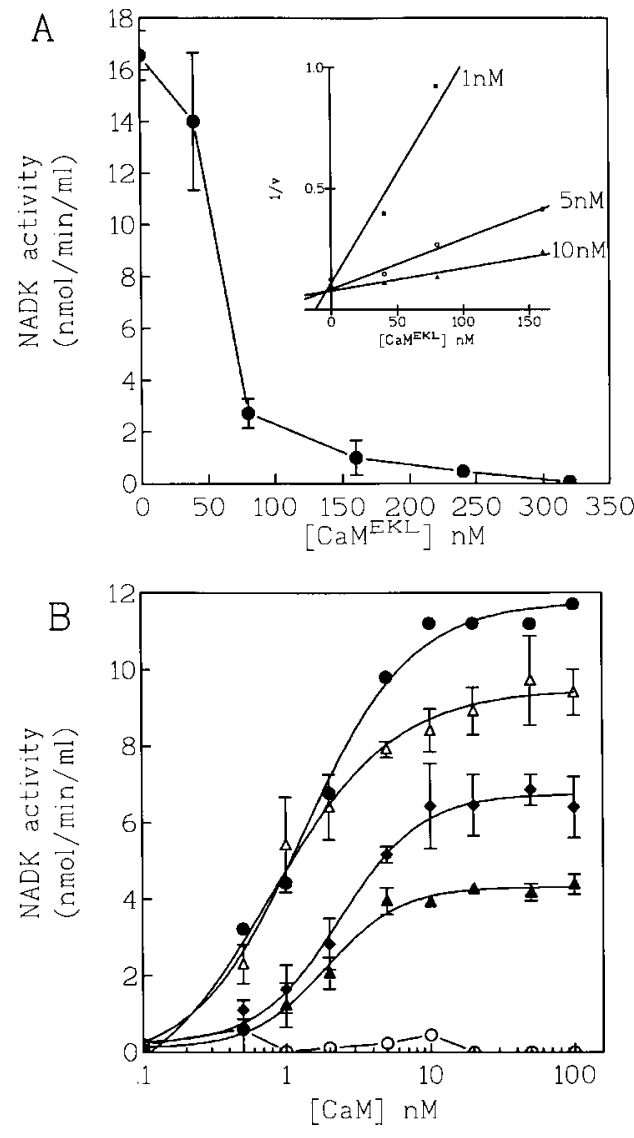

Figure 5 Interaction of CaM EKL and Q41E, N42K, P43L calmodulins with
NADK

(A) Activation of NADK by $100 \mathrm{nM}$ VU-1 in the presence of varing amounts of CaM ${ }^{\mathrm{EKL}}$. The inset shows a Dixon plot of the activation of NADK in the presence of fixed concentrations of VU-1 and increasing amounts of CaM ${ }^{\mathrm{EKL}}$., $1 \mathrm{nM}$ VU-1; O, $5 \mathrm{nM} \mathrm{VU-1;} \boldsymbol{\Delta}, 10 \mathrm{nM} \mathrm{VU-1}$ (B) Activation of NADK by VU-1 $(\mathbf{O}), \mathrm{CaM}^{\mathrm{EKL}}(\mathrm{O})$, Q41E $(\mathbf{\Delta})$, N42K $(\triangle)$, and $(\bullet)$ P43L. All assays were carried out in $1 \mathrm{mM} \mathrm{CaCl}$. Means \pm S.E.M. are shown.

of $\mathrm{CaM}^{\mathrm{EKL}}$ to activate NADK is due to the cumulative effect of the three substitutions, and is not due to any single amino acid change.

\section{Effects of substituting EF hands I and II into the C-terminal lobe using $\mathrm{CaM}^{1214}$ and $\mathrm{CaM}^{1232}$}

$\mathrm{CaM}^{1214}$ and $\mathrm{CaM}^{1232}$ were constructed by generating a cassette containing EF hand I or EF hand II by PCR, and replacing the coding regions for EF hands III or IV respectively in VU-1 (Figure 1B). Both calmodulins were functional and activated PDE and NAD kinase (Figure 6). $\mathrm{CaM}^{1214}$ activates PDE to the same extent as VU-1 (Figure 6A), however, the $K_{0.5}^{\mathrm{CaM}}$ for the activation is two-fold higher (Table 1). $\mathrm{CaM}^{1232}$ activates PDE to only $52 \%$ of the level of VU-1 and also shows a slight shift in the $K_{0.5}^{\mathrm{CaM}}$ (Figure 5A, Table 1). $\mathrm{CaM}^{1214}$ and $\mathrm{CaM}^{1232}$ also show a lower NADK activation, activating the enzyme to $66 \%$ and $79 \%$ respectively of the level obtained with VU-1 (Figure 6B, Table 1). Furthermore, calcium dependence for enzyme activation by VU-1, $\mathrm{CaM}^{1232}$ and $\mathrm{CaM}^{1214}$ show similar $K_{0.5}^{\mathrm{Ca} 2+}$ values between 90 and $150 \mathrm{nM}$ (Figure 6C, Table 1), suggesting that these domain substitutions do not drastically compromise calcium binding activity. 

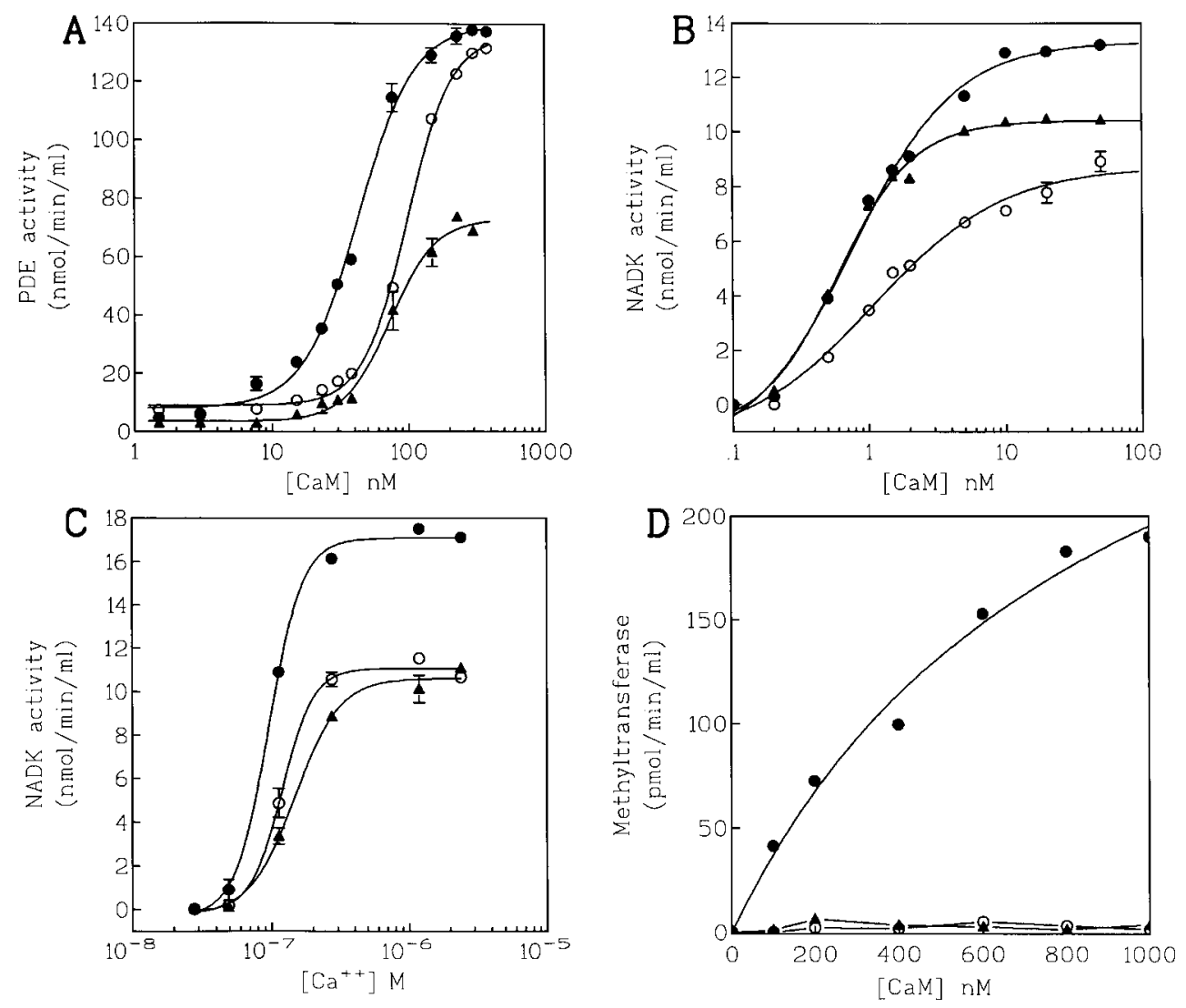

\section{Figure 6 Enzyme activation by and methylation of $\mathrm{CaM}^{1214}$ and $\mathrm{CaM}^{1232}$}

Activation of (A) PDE and (B) NADK in $1 \mathrm{mM} \mathrm{CaCl}$, with varied concentrations of calmodulin. (C) Activation of NADK by $50 \mathrm{nM}$ of each calmodulin with varied concentrations of free calcium using the EGTA/Ca ${ }^{2+}$ buffering system described in the Materials and methods section. (D) Pseudo-first-order methyltransferase kinetics at a constant saturating concentration of $S$ adenosylmethionine $(12 \mu \mathrm{M})$ with calmodulin as the varied substrate, and carried out in $1 \mathrm{mM} \mathrm{CaCl}_{2}$. Means \pm S.E.M. are shown. $\boldsymbol{\bullet}, \mathrm{VU}-1 ; \mathrm{O}, \mathrm{CaM}^{1214} ; \boldsymbol{\Delta}, \mathrm{CaM}^{1232}$.

In contrast to the modest effects on enzyme activation, neither $\mathrm{CaM}^{1232}$ nor $\mathrm{CaM}^{1214}$ serves as a substrate for methylation by the calmodulin methyltransferase (Figure 6D). Together with the data for $\mathrm{CaM}^{\mathrm{EKL}}$, these findings suggest that amino acid residues unique to both EF hands III and IV are required for recognition by the calmodulin methyltransferase.

\section{DISCUSSION}

\section{Calmodulin methyltransferase recognition}

Previous studies have shown that a tryptic fragment of calmodulin comprising residues $78-148$ is sufficient for methyltransferase recognition and Lys $^{115}$ methylation with kinetics indistinguishable from those with intact calmodulin [17]. Thus, the residues that comprise the recognition site for calmodulin methyltransferase are localized to the C-terminal lobe of the molecule. The loop region (residues 112-117) containing the unique site of methylation is highly conserved among calmodulins, and is a logical place to begin to investigate residues required for methyltransferase binding and recognition.

The methylation loop (LGEKLT) sequence represents a turn between adjacent EF hands III and IV. The turn appears to be facilitated by $\operatorname{Gly}^{113}\left(\Phi / \psi=93^{\circ} / 10^{\circ}[30]\right)$, which explains the high conservation of glycine at this position. Additionally, the loop conformation appears to be stabilized by hydrogen bonding between the backbone amide nitrogens of $\mathrm{Gly}^{113}$ and $\mathrm{Glu}^{114}$ and the backbone carbonyl oxygens of $\mathrm{Met}^{109}$ and $\mathrm{Thr}^{110}$ in helix $6(\mathrm{~F}$ helix of EF hand III, Figure 1) [30]. In addition, the side chain of Lys ${ }^{116}$ in the loop sequence is embedded in the core of the C-terminal lobe where it forms hydrophobic interactions with residues on the hydrophobic faces of the helices of EF hands III and IV [1]. Lys ${ }^{115}$ is solvent exposed and does not appear to form contacts with any other part of the calmodulin structure [1,31].

The present results show that the two residues that flank the site of methylation appear to be essential for methyltransferase recognition, but not for calmodulin activation of the two enzymes tested. The replacement of $\mathrm{Leu}^{116}$ with the more polar side chain of threonine would most likely disrupt the interaction of the methylation loop with the hydrophobic core, and this apparently results in a loss of recognition and methylation by the enzyme. Substitution of the negatively charged, solvent exposed Glu ${ }^{114}$ with uncharged alanine also abolishes Lys ${ }^{115}$ methylation. Previous work [17] has suggested that electrostatic interactions help stabilize the interaction of calmodulin with the methyltransferase, and the loss of the negatively charged, surface exposed glutamate may eliminate a point of contact for the enzyme.

While the conserved sequence of the methylation loop (LGEKLT) appears to be essential for methyltransferase recognition, it is clear that other structural determinants outside of this region are also essential for methyltransferase binding. This is supported by the finding with $\mathrm{CaM}^{\mathrm{EKL}}$, which is not recognized and methylated by the calmodulin methyltransferase. Based on a comparison of the backbone structure of residues 39-44 and 
112-117 (Figure 3), the loop sequence introduced into the Nterminal lobe of $\mathrm{CaM}^{\mathrm{EKL}}$ should have a similar conformation to the methylation loop in native calmodulin. Thus, the inability of the enzyme to methylate $\mathrm{CaM}^{\mathrm{EKL}}$ strongly suggests that additional determinants outside of the loop are essential for methyltransferase binding and catalysis.

This conclusion is further supported by the results with the domain exchange mutants $\mathrm{CaM}^{1214}$ and $\mathrm{CaM}^{1232}$, neither of which serve as a substrate for methylation. As pointed out previously, the backbone structures of the EF hand pair I and II are very similar to those of EF hand pair III and IV (root-meansquare difference of $0.751 \AA$, [1]). In addition, the present study, as well as previous work [32], shows that the exchange of EF hands between the $\mathrm{N}$ - and $\mathrm{C}$-terminal lobes produces folded, functional calmodulin proteins. Thus, the lack of the ability of the two EF hand exchange mutants to be methylated is most likely due to the requirement for specific structural determinants unique to both EF hands III and IV, which are missing in both $\mathrm{EF}$ hands I and II. The exchange of subdomains (e.g., E or F helices or loop regions) between EF hands, or the substitution of highly conserved residues unique to both EF hands III or IV, will provide future insight regarding these specific structural determinants.

\section{Determinants for the activation of NADK}

The present study sheds new light on residues important for the activation of NADK. CaM ${ }^{\mathrm{EKL}}$ does not activate NADK but is a potent antagonist of activation by wild-type calmodulin, suggesting binding but not activation of the enzyme. Calmodulin derivatives that have similar antagonist activities with other calmodulin-dependent enzymes have been generated via chemical modification [33], the production of troponin $\mathrm{C} /$ calmodulin chimaeras [34-38] or by EF hand duplication within calmodulin [32,39].

From these observations, it has been proposed that calmodulin activation of enzymes follows a two step mechanism. Initially, calcium interaction with calmodulin leads to interaction with the calmodulin binding domain of the enzyme ([6,7]; reviewed in [40]) that is followed by additional specific interactions which lead to activation $[35,41]$. The structural determinants for this latter process are proposed to form after calmodulin binding, and recent evidence has implicated a region of calmodulin known as the 'latch domain'. During target protein-peptide binding, the $\mathrm{N}$ - and $\mathrm{C}$-terminal lobes of calmodulin converge, forming a hydrophobic channel that surrounds the peptide [6,7]. In the peptide bound structure, helix 2 (EF hand I) interacts with helix 6 (EF hand III), forming a 'latch', linking the two lobes of calmodulin [6].

Site-directed mutagenesis studies have shown that residues within helix 2 and helix 6 are essential for activation of calmodulin-dependent enzymes [35-38]. Interestingly, however, specific mutations within the latch domain region show a differential effect on the activation of various calmodulindependent enzymes. Thus while it is clear that this domain is important in the activator activity of calmodulin, each target enzyme has a distinct set of structural determinants for activation.

By using a chimaeric approach with soybean calmodulin (SCaM-1) and a calmodulin-like protein (SCaM-4), residues within helix 2 in EF hand I were implicated as being important for activation of NADK [42]. The present study shows that additional residues in the loop-turn region between EF hands I and II adjacent to helix 2 also play a critical role in activation. The substitution of QNP to EKL in $\mathrm{CaM}^{\mathrm{EKL}}$ is predicted to result in the same backbone conformation (Figure 3), suggesting that the defect is probably not due to a disruption of calmodulin conformation in this region. Since these residues are localized close to the latch domain, it is possible that they form part of the structure that is required for activation of NADK upon calmodulin binding. Among the residues in the QNP triad, the mutation Q41E appears to exert the greatest effect on activity, suggesting that the introduction of a negative charge for the conserved amide at position 41 affects NADK activation. Additionally, the replacement of the conserved $\mathrm{Pro}^{43}$ residue with leucine, a larger branched hydrophobic residue, also shows a significant decrease in activation. Evidence for the importance of residue 43 in calmodulin function also comes from genetic studies of Drosophila melanogaster in which a point mutation of Pro $^{43} \rightarrow$ Leu in calmodulin results in enhanced lethality and abnormal behavioural characteristics [43].

Interestingly, the symmetry related methylation loop sequence (EKL) also appears to be important in activation. The present study shows that the E114A and L116T mutations have only a slight effect on NADK activation. In contrast, Lys ${ }^{115}$ appears to have a greater effect on NADK, since trimethylation drastically lowers the level of activation of NADK $[9,10,23,44]$. This posttranslational modification has little effect on other calmodulindependent enzymes, again emphasizing the unique nature of the determinants for activation of the various calmodulin-dependent enzymes.

As a final point, the use of mutant calmodulins that selectively hyperactivate NADK in transgenic plants has been instructive in the analysis of its function in vivo in plant defence responses $[12,13]$. Based on the present work, $\mathrm{CaM}^{\mathrm{EKL}}$ may be useful as a potential antagonist of NADK for similar in vivo studies.

This work was supported by United States Department of Agriculture grants 9237304-7874 and 97-35305-4744 to D. M. R.

\section{REFERENCES}

Babu, Y. S., Bugg, C. E. and Cook, W. J. (1988) J. Mol. Biol. 204, 191-204

2 Persechini, A. and Kretsinger, R. H. (1988) J. Biol Chem. 263, 12175-12178

3 Barbato, G., Ikura, M., Kay, L. E., Pastor, R. W. and Bax, A. (1992) Biochemistry 31, 5269-5278

4 Watterson, D. M., Sharief, F. and Vanaman, T. C. (1980) J. Biol. Chem. 255, 962-975

5 Kuboniwa, H., Tjandra, N., Grzesiek, S., Ren, H., Klee, C. B. and Bax, A. (1995) Nature Struct. Biol. 2, 768-776

6 Meador, W., Means, A. R. and Quiocho, F. (1992) Science 257, 1251-1255

7 Ikura, M., Clore, G. M., Gronenborn, A., Zhu, G., Klee, C. and Bax, A. (1992) Science 256, 632-638

8 Siegel, F. L., Vincent, P. L., Neal, T. L., Wright, L. S., Heth, A. A. and Rowe, P. M. (1990) in Protein Methylation (Paik, W. K. and Kim, S., eds.), pp. 33-58, CRC Press, Boca Raton

9 Roberts, D. M., Rowe, P. M., Siegel, F. L., Lukas, T. J. and Watterson, D. M.(1986) J. Biol. Chem. 261, 1491-1494

10 Roberts, D. M., Besl, L., Oh, S. H., Masterson, R. V., Schell, J. and Stacey, G. (1992) Proc. Natl. Acad. Sci. U.S.A. 89, 8394-8398

11 Gregori, L., Marriot, D., West, C. M. and Chau, V. (1985) J. Biol. Chem. 260, 5232-5235

12 Harding, S., Oh, S. H. and Roberts, D. M. (1997) EMBO J. 16, 1137-1144

13 Harding, S. A. and Roberts, D. M. (1998) Planta 206, 253-258

14 Takeda, T., Imai, Y. and Yamamoto, M. (1989) Proc. Natl. Acad. Sci. U.S.A. 86, 9737-9741

15 Rowe, P. M., Wright, L. S. and Siegel, F. L. (1986) J. Biol. Chem. 261, 7060-7069

16 Morino, H., Kawamoto, T., Miyake, M. and Kakimoto, Y. (1987) J. Neurochem. 48, 1201-1208

17 Han, C. H., Richardson, J., Oh, S. H. and Roberts, D. M. (1993) Biochemistry 32 13974-13980

18 Pech, L. L. and Nelson, D. L. (1994) Biochim. Biophys. Acta 1199, 183-194

19 Wright, L. S., Bertice, P. J. and Siegel, F. L. (1996) J. Biol. Chem. 271, 12737-12743 
20 Han, C.H and Roberts, D. M. (1997) Eur. J. Biochem. 244, 904-912

21 Lukas, T. J., Friedman, M. W., Kung, C. and Watterson, D. M. (1989) Proc. Natl. Acad. Sci. U.S.A. 86, 7331-7335

22 Lukas, T. J., Craig, T. A., Roberts, D. M., Watterson, D. M., Haiech, J. and Prendergast, F. G. (1987) in Calcium Binding Proteins in Health and Disease (Carafoli, E., Imesin, G., Means, A. R., Norman, A. W., Siegel, F. L., Suttie, J. W. and Vanaman, T. C., eds.), pp. 533-543, Academic Press, San Diego

23 Roberts, D. M., Crea, R., Malecha, M., Alvarado-Urbina, G., Chiarello, R. H. and Watterson, D. M. (1985) Biochemistry 24, 5090-5098

24 Sambrook, J., Fritsch, E. F. and Maniatis, T. (1989) Molecular Cloning: A Laboratory Manual, Cold Spring Harbor Laboratory Press, Cold Spring Harbor, New York

25 Roberts, D. M., Zimmer, W. E. and Watterson, D. M. (1987) Methods Enzymol. 139, 290-303

26 Sharma, R. K., Wang, T. H., Wirch, E. and Wang, J. H. (1981) J. Biol. Chem. 255 5916-5923

27 Grynkiewicz, G., Poenie, M. and Tsien, R. Y. (1985) J. Biol. Chem. 260, 3440-3450

28 Crouch, T. H. and Klee, C. B. (1980) Biochemistry 19, 3692-3698

29 Oh, S. H. and Roberts, D. M. (1990) Plant Physiol. 93, 880-887

30 Chattopadhyaya, R., Meador, W. E., Means, A. R. and Quiocho, F. A. (1992) J. Mol. Biol. 228, 1177-1192

31 Zhang, M., Huque, E. and Vogel, H. J. (1994) J. Biol. Chem. 269, 5099-5105
32 Persechini, A., Stemmer, P. and Ohashi, I. (1996) J. Biol Chem. 271, 32217-32225

33 Newton, D. L., Burke, Jr., T. R., Rice, K. C. and Klee, C. B. (1983) Biochemistry 22 , 5472-5476

34 George, S. E., Van Berkum, M., Ono, T., Cook, R., Hanley, R., Putkey, J. and Means, A. R. (1990) J. Biol. Chem. 265, 9228-9235

35 Van Berkum, M. and Means, A. (1991) J. Biol. Chem. 266, 21488-21495

36 George, S. E., Su, Z., Fan, D. and Means, A. R. (1993) J. Biol. Chem. 268, 25213-25220

37 Su, Z., Fan, D. and George, S. (1994) J. Biol. Chem. 269, 16761-16765

38 Su, Z., Blazing, M., Fan, D. and George, S. (1995) J. Biol. Chem. 270, 29117-29122

39 Persechini, A., Gansz, K. J. and Paresi, R. J. (1996) Biochemistry 35, 224-228

40 Ikura, M. (1996) Trends Biochem. Sci. 21, 14-17

41 Blumenthal, D. K. and Stull, J. T. (1982) Biochemistry 21, 2386-2391

42 Lee, S. H., Seo, H. Y., Kim, J. C., Heo, W. D., Chung, W. S., Lee, K. J., Kim, M. C., Cheong, Y. H., Choi, J. Y., Lim, C. O. and Cho, M. J. (1997) J. Biol.Chem. 272 9252-9259

43 Nelson, H. B., Heiman, R. G., Bolduc, C., Kovalick, G. E., Whitley, P., Stern, M. and Beckingham, K. (1997) Genetics 147, 1783-1798

44 Roberts, D. M., Burgess, W. H. and Watterson, D. M. (1984) Plant Physiol. 75, 796-798

Received 4 January 1999/8 February 1999; accepted 12 March 1999 